DE91 011094

\title{
DESIGN ASPECTS FOR A PULSED-MODE, HIGH-INTENSITY, HEAVY NEGATIVE ION SOURCE
}

\author{
G. D. ALTON \\ Oak Ridge National Laboratory* \\ Oak Ridge, TN 37831-6368
}

\begin{abstract}
A high-intensity, plasma-sputter, negative ion source, which utilizes multi-cusp, magnetic-field, plasma-confinement techniques, has been designed at the Oak Ridge National Laboratory (ORNL). The source is an axial-geometry version of the radial-geometry source which has demonstrated pulsedmode peak intensity levels of several $\mathrm{mA}$ for a wide spectrum of heavy negative ion species. The mechanical design fearures include provisions for fast interchange of sputter samples, ease of maintenance, direct cooling of the discharge chamber, and the use of easily replaced coaxial $\mathrm{LaB}_{6}$ cathodes.

\section{INTRODUCTION}

The radial-geometry, plasma-sputter, negative ion source, described in Refs. 1-5, has demonstrated the capability of producing high-intensity (several $\mathrm{mA}$ ) pulsed beams of a wide spectrum of atomic and molecular negative ion species and also has shown promisc for operation in dc mode. ${ }^{5}$ The pulsed-mode performance characteristics of this source type are particularly well suited for use in conjunction with the tandem electrostatic accelerator when used as an injector for a heavy ion synchrotron, while the dc mode of operation is commensurate with stand-alone tanden accelerator cperation. For heavy ion synchrotron injection applications, highintensity, pulsed beams of widths $50-300$ us at repetition rates of $1.50 \mathrm{~Hz}$ for a wide spectrum of atornic and molecular species are typically required.
\end{abstract}

\section{SOURCE DESIGN}

The high-intensity, radial-geometry, plasma-sputter, negative ion source, described in Refs. 1-5, has proved to be a reliable, stably operating source with a long lifetime for pulsed-mode operation. The intensity levels obtained are often higher, by factors of 30-100, than those which can be generated in cesium sputier-type sources such as described in Refs. 6.8 and yet the emittances of beams provided by the source are comparable for pulsed-mode operation to those provided by conventional sputter-type sources. ${ }^{9}$ The emittances of these beams aiso match the calculated acceptances of large tandem accelerators such as the 25URC tandicm accelerator at ORNL. ${ }^{10}$

The operational characteristics of the axial-geometry source, shown in Fig. 1, are expected to be identical in almost

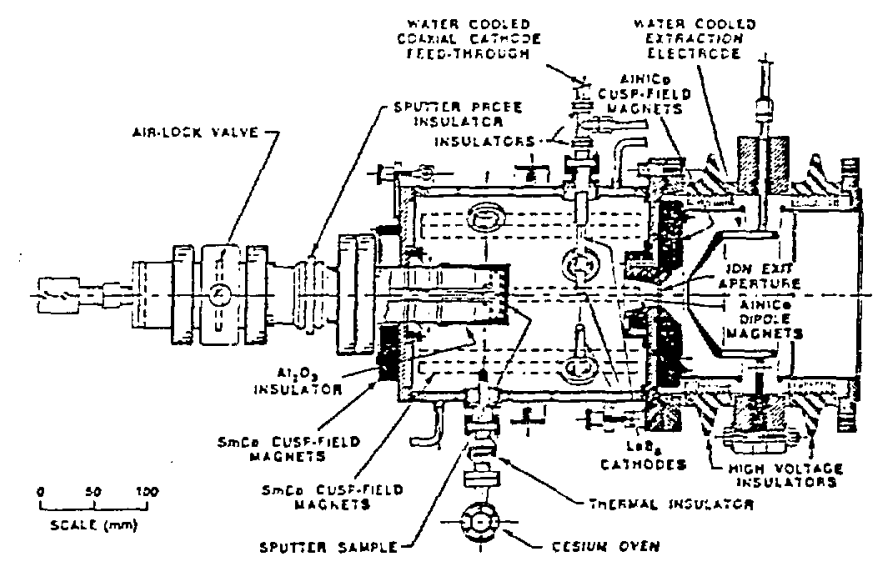

Fig. 1. Axial-geometry, plasma-sputter, negative ion source (top view).

every detail to the radial-geometry source. ${ }^{1-5}$ The source is constructed primarily of stainless steel and utilizes metal-toceramic bonded high-voltage insulators and low-voltage feedthroughs. Design emphasis has been placed on the ability to rapidly change the source itself and all degradable components, The cesium oven is mounted externally, permitting easy access for servicing, while providing good thermal isolation between the discharge chamber and the oven itself. The main source can be quickly and easily disassembled for cleaning and other maintenance operations. The source assembly is composed of four major independent assemblies: (1) the sputter probe vacuum airlock assembly: (2) a freon-cooled, stainiess sicel discharge chamber onto

* Research sponsored by the U.S. Department of Energy under contract DE-AC05-84OR21400 with Martin Marietta Energy Sy'sicms, Inc. 
which is attached the cesium oven, discharge gas support sy'stem, coaxial geometry $\mathrm{LaB}_{6}$ cathodes, and $\mathrm{SmCo}$ and AlNiCo plasma confinement magnets, (3) a ceramic-to-metal bonded alumina $\left(\mathrm{Al}_{2} \mathrm{O}_{3}\right)$ insulator to which is attached the high-voltage extraction electrode system, and (4) the coexial $\mathrm{LaB}_{6}$ cathode assembly. The power supply arrangement required for operation of the source is shown in Fig. 2.

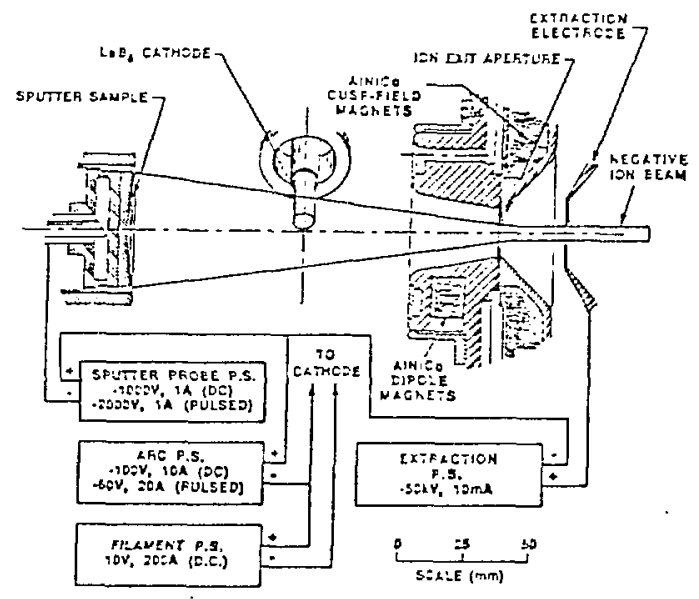

Fig. 2. Pow'er supply arrangement for the axial-geometry, plasma-sputter, negative ion source.

\section{SPUTTER PROBE VACUUM AIRLOCK ASSEMBLY}

The sputter probe assembly consisls of a thin wall, 12.7 . mm-diameter chromium plated copper tube to which is attached the 50 - $\mathrm{mm}$-diameter copper sample holder onto which is clamped the material of interest. The sample holder is cooled by continuous freon flow through a concentric tuhe arrangement. The probe can be inserted into and withdrawn from the source through the airlock valve which is sealed against atmospheric pressure by a conventional elastomer gasket. The vacuum interlock asscmbly is attached to an externally mounted ceramic-to-metal insulator which in turn is fastened to the back flange of the source. The insulator is used to isolate the probe-vacuum airlock assembly from the source body. Based on experience with sources equipped with similar provisions, the total time required for withdrawing, replacement, and reinsertion of the sputter probe sample material is expected to be the order of 10 minutes.

The sputter probe/airlock assembly is insulated from the source housing with an insulator designed to withstand potentials up to $-5 \mathrm{kV}$. When fully inserted into the discharge chamber, the sputter probe is surrounded by an $\mathrm{Al}_{2} \mathrm{O}_{3}$ insulating sleeve which prevents all internal negatively biased components other than the sumple material from baing bombarded by positive ions extracted from the surrounding plasma. Two geometries of sputter samples will be utilized. In cases where malleable mctal sheet material containirg the species of interest is readily available, siniples $1-1.5 \mathrm{~mm}$ in thickness will the pressed by means of a die fixiure inio a 50 -mm-diameter spherical sector probe with radius of curvature $\rho=210 \mathrm{~mm}$ for focusing the negative ion berm generated in the sputtering process through the exit aperture of the source. Samples which are brittle must be formed from solid materials. Composite sintered compounds or mixtures of compounds will be typically $5 \mathrm{~mm}$ in thickness with a spherical radius of $210 \mathrm{~mm}$ machined into the face of the material. These samples will be indirecly cooled by clamping the sample to a spherical or flat geometry copper heat sink appropriatcly contoured to the respective sample geometry. The sputter probe assembly will ie cooled by a freon heat exchange unit maintained at $15^{\circ} \mathrm{C}$.

\section{VACUUM DISCHARGE CHAMBER AND PLASMA CONFINEMENT ARRANGEMENT}

The vacuum/discharge chamber is made of stainless steel equipped with freon coolant passages to protect the ten sets of equally spaced SmCo and AINiCo plasma discharge confinement magnets from thermal degradation by the radiant power incident on the walls of the chamber arising from the plasma discharge and high temperature $\mathrm{LaB}_{6}$ cathodes. Plasma confinement is effected by the use of ten row's of SmCo permanent magnets, equally spaced circumferentially around the diameter of the cylindrical chamber. The external and internal flanges of the chamber are equipped with ten equally spaced, azimuthally oriented $\mathrm{SmCo}$ and $\mathrm{AlNiCo}$ magnets, respectively. The internal flange is equipped with a set of dipole AlNiCo magnets to inhibit electron extraction from the source and thereby reduce loading to the extraction power supply and a replaceable tantalum aperture. Initially, the exit aperture will be $10 \mathrm{~mm}$. The chamber is attached to the rear and front flanges by means of thumb screw's for ease in disassembly for cleaning and other mantenance operations.

\section{COAXIAL LaB6 ASSEMBLY}

The source will utilize direclly heated coaxial-geometry $\mathrm{LaB}_{6}$ cathodes to initiate and sustain tie plasma discharge. The cathode structure is very similar to the design described by Leung et al. in Ref. 11. The high melting point, chemical inertness, low work function, and low sputter ratio properties make $\mathrm{LaB}_{6}$ especially attractive for such applications. The coaxial geometry is desirable because it minimizes the magnetic ficld surrounding the cathode and thus permits emission and escape of low-energy electrons from the surface. More importantly, the design allows easy and fast interchange of cathodes through a single metal-to-metal racuum seal feed through.

\section{THE ION EXTRACTION ELECTRODE SYSTEM AND EXTRACTION OPTICS}

One of the advantages of the plasnia-ijpe sputter regative icn source lics in the fact thet, ‥ten onstact in a high-dersity plasma mode, the negatively biased spuiler probe 
containing the material of interest is unifornlly sputtered. Negative ions created in the sputter process are accelerited and focused through the plasma to a common focal mint, usually chosen as the ion exit aperture of the source, and then pass into the ficld region of the extraction clectrode system. Within the plasma, the ion beam is free of space charge effects which only become important upon exit from the pla.ma region of the source. Since the beam encrgy is $500-1000 \mathrm{eV}$ upon exit from the plasma region of the source, space churge influences on the beam are reduced. After cxiting the source, the beam is further accelerated by a two-stage electrode system insulated by high-quality $\mathrm{Al}_{2} \mathrm{O}_{3}$ insulators. Typically, the ion beam will be accelerated through a potential difference of $20 \mathrm{kV}$ in the first stage and by an additional $30 \mathrm{kV}$ in the second stage.

The ion optics of the ion generation and extraction regions of the source have been studicd computationally through use of the code described in Ref. 12. Examples of such calculations which display ion trajectorics for a $3.5-\mathrm{mA} \mathrm{O}^{-}$or a 1-mA $\mathrm{Au}^{-}$ion beam are show'n in Fig. 3. Negative ions,

ION ENEFGY: $51 \mathrm{keV}$; 1ON BEALS IRTENSITY: $0^{\circ}: 3.5 \mathrm{~mA}$; 4U": INA

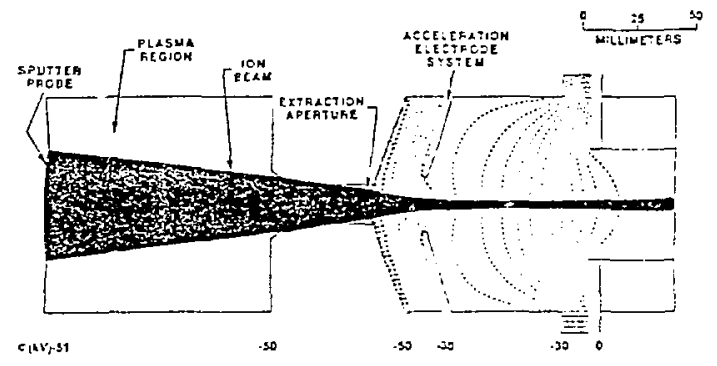

Fig. 3. Negative ion optics of the axial-geometry, sputter heavy negative ion source cquipped with a two-stage extraction electrode system shown in Fig. 1. Ion beam:

$3.5 \mathrm{~mA} \mathrm{O}^{-}$or $1 \mathrm{~mA} \mathrm{Au}$; ion energy: $51 \mathrm{keV}$.

generated at the sputter probe surface and accelerated across the plasma sheath, drift through the field-free region of the plasma and exit into the extraction lens system where they are accelerated further to energies up to $51 \mathrm{keV}$. The characteristics of $\mathrm{mA}$-intensity-level ion beams in the extraction region of the source are found to be dominated by space charge effects.

\section{EXPECTED PERFORMANCE OF THE SOURCE}

The operational parameters and intensity capabilities of the subject source are expected to be similar to those of the radial-geometry source and therefore, the reader is referred to Refs. 1-5 for specific information concerning the species and intensity capabilitics, as well as the qualitics (cmittances) of beams produced in this type of source. The anticipated operational parameters for pulsed-mode operation of the source are shown in Table 1. For cxample, the source is expected to generate peak beam intensities close to those reported in Ref. \& for the radial-geometry source, which includes a list of more than 20 negative ion speciss, induding $6 \mathrm{~mA} \mathrm{C}, 10 \mathrm{~mA} \mathrm{Cu}-8 \mathrm{~mA} \mathrm{Pt}^{-}$; and $10 \mathrm{~mA} \mathrm{Au}^{-}$. Tho emittances of heam: extracted from the sulece are aloo expected to be close to those of the radial-geometry source (lypically, $11-17 \pi \mathrm{mm}$ mirad $(.9 \mathrm{cV})^{1 / 2}$ at the 805 contour level, depending on 4 : heam intensity).

\section{ACKNOWLETYENENTS}

The author is indebled to Dr. K. N. Leung for supplying inforrnation concerning the coaxial $\mathrm{LaB}_{6}$ cathode assembly design used at Law'rence Berkeley Laboratory.

Table 1. Expected pulsed-mode source operating paramelers.

$\begin{array}{ll}\text { Arc current } & 15-20 \mathrm{~A} \\ \text { Arc voltage } & 30-60 \mathrm{~V} \\ \text { LaB6 cathode current } & 130 \mathrm{~A} \\ \text { LaB6 cathode temperature } & 1450^{\circ} \mathrm{C} \\ \text { Xe gas pressure } & 2.3 \times 10^{-4} \mathrm{Tcr} \\ \text { Sputter probe voltage } & 500 \mathrm{~V} \\ \text { Beam extraction voltage } & 50 \mathrm{kV} \\ \text { Cesium oven temperature } & 190-205^{\circ} \mathrm{C} \\ \text { Bcam pulse width } & 1-5 \mathrm{~Hz} \\ \text { Repetition rate } & 1.50 \mathrm{~Hz}\end{array}$

\section{REFERENCES}

1. G. D. Alton, Y. Mori, A. Takagi, A. Ueno, and S. Fukumoto, Nucl. Instrum. and Meth. A270 (1988) 194.

2. Y. Mori, G. D. Alton, A. Takagi, A. Ueno, and S. Fukumoto, Nucl. Instrum. and Mcth. A273 (1988) 5.

3. G. D. Alton, Y. Mori, A. Takagi, A. Ueno, and S. Fukumoto, Nucl. Instrum. and Meth. B40/A1 (1989) 1008.

4. G. D. Alton, Y. Mori, A. Takagi, A. Ueno, and S. Fukumoto, Rev. Sci. Instrum. 61 (1990) 372.

5. Y. Mori, A. Takagi, A. Ueno, K. lkegami, and S. Fukumoto, Nucl. Insirum. and Meth. A278 (1989) 605.

6. G. D. Alton, Nucl. Instrum. and Meth. B37/38 (1989) 45 .

7. G.D. Alton, IEEE Cat. No. 8:CH2669-0, Vol. 2 (1989) 1112 .

8. G. D. Alton, Nucl. Instrum. and Mcth. A287 (1990) 139.

9. G. D. Alten, Phys. Div. Progress Report, ORNL-6120 (1987) p. 222.

10. J. D. Larson and C. M. Jones, Nucl. Instrum. and Meth. $140(1977) 489$.

11. K. N. Leung, D. Moussa, and S. B. Wilde, Rev. Sci. Instrum. 57 (1986) 1274.

12. J. H. Whealton, Nucl. Instrum. and Meth. 189 (1981) 55 . 